\title{
Letter from the Editor: A Daunting Task
}

\author{
Gary W. Felton ${ }^{1}$
}

Published online: 2 March 2017

(C) Springer Science+Business Media New York 2017

When John Romeo approached me more than a year ago about the possibility of becoming the new editor-in-chief, I was frankly shocked. JCE has been extremely fortunate to be in the hands of excellent Editors since its inception in 1975: Milt Silverstein and John Simeone as founding Editors, followed by co-Editors Jim Nation, David Jones and John Romeo, and then John Romeo as Editor-in-Chief.

These are difficult shoes to fill! For 20 years as co-Editor and Editor, John has served JCE with distinction. The impact factor of the journal has taken anoticeable jump in the last few years and John deserves the credit while keeping the standards of the journal high.

The interdisciplinary focus of the journal has always been attractive to me. My first publication during my Ph.D. was in JCE; my first graduate student, Jianlong Bi published his first paper in JCE; my first graduate student at Penn State, Feng Liu, published her first paper in JCE, and my highest cited paper in my career is in JCE.
Over the years working with all of the Editors, I've had the good fortune to publish what I believe are some of my lab's best papers in JCE. It is for this gratitude that I felt the nudge to accept the position.

I do not expect the focus of the journal to undergo any significant change; although the nature of the field, of course, is constantly evolving. There are many scientists worldwide who are conducting "chemical ecology" related research and yet may never think of themselves as chemical ecologists. During the next year, I hope through Special Issues and other means to broaden the audience that may be exposed to the journal.

I sincerely thank John Romeo and his editorial assistant Joseph Deluca for their invaluable assistance and patience through the transition. Fortunately, we have a superb group of Associate Editors and Editorial Board Members to support the journal. I look forward to working with them to ensure the quality and the impact of JCE remains high.
Gary W. Felton

gwf10@psu.edu

1 Department of Entomology, Center for Chemical Ecology, Penn State University, University Park, PA, USA 